\title{
Gene-diet interactions on plasma lipid levels in the Inuit population
}

\author{
Iwona Rudkowska ${ }^{1,2}$, Eric Dewailly ${ }^{3}$, Robert A. Hegele ${ }^{4}$, Véronique Boiteau ${ }^{3}$, \\ Ariane Dubé-Linteau ${ }^{3}$, Belkacem Abdous ${ }^{3}$, Yves Giguere ${ }^{3}$, Marie-Ludivine Chateau-Degat ${ }^{3}$ and \\ Marie-Claude Vohl ${ }^{1,2 *}$ \\ ${ }^{1}$ Institute of Nutraceuticals and Functional Foods (INAF), Laval University, Pavillon des Services, Bureau 2729K, \\ 2440, Boulevard Hochelaga, Quebec City, QC, Canada G1V OA6 \\ ${ }^{2}$ Laboratory of Endocrinology and Genomics, Laval University Hospital Research Center, Quebec City, QC, Canada \\ ${ }^{3}$ Laboratory of Population and Environmental Health, Laval University Hospital Research Center, Quebec City, QC, Canada \\ ${ }^{4}$ Robarts Research Institute, London, ON, Canada
}

(Submitted 18 November 2011 - Final revision received 2 March 2012 - Accepted 22 April 2012 - First published online 5 July 2012)

\section{Abstract}

The Inuit population is often described as being protected against CVD due to their traditional dietary patterns and their unique genetic background. The objective of the present study was to examine gene-diet interaction effects on plasma lipid levels in the Inuit population. Data from the Qanuippitaa Nunavik Health Survey ( $n$ 553) were analysed via regression models which included the following: genotypes for thirty-five known polymorphisms (SNP) from twenty genes related to lipid metabolism; dietary fat intake including total fat (TotFat) and saturated fat (SatFat) estimated from a FFQ; plasma lipid levels, namely total cholesterol (TC), LDL-cholesterol (LDL-C), HDL-cholesterol (HDL-C) and TAG. The results demonstrate that allele frequencies were different in the Inuit population compared with the Caucasian population. Further, seven SNP ( $A P O A 1$ - 75G/A (rs670), APOB XbAI (rs693), AGT M235T (rs699), LIPC 480C/T (rs1800588), APOA1 84T/C (rs5070), PPARG2 - 618C/G (rs10865710) and APOE 219G/T (rs405509)) in interaction with TotFat and SatFat were significantly associated with one or two plasma lipid parameters. Another four SNP (APOC3 3238C > G (rs5128), CETP I405V (rs5882), CYP1A1 A4889G (rs1048943) and ABCA1 Arg219Lys (rs2230806)) in interaction with either TotFat or SatFat intake were significantly associated with one plasma lipid variable. Further, an additive effect of these SNP in interaction with TotFat or SatFat intake was significantly associated with higher TC, LDL-C or TAG levels, as well as with lower HDL-C levels. In conclusion, the present study supports the notion that gene-diet interactions play an important role in modifying plasma lipid levels in the Inuit population.

\section{Key words: Saturated fat: Total fat: Total cholesterol: LDL-cholesterol: HDL-cholesterol: TAG: Polymorphisms}

The Inuits are frequently described as being somehow protected from CVD through their traditional diet and lifestyle ${ }^{(1)}$. Yet, the recent adoption of a Westernised lifestyle has been associated with an increase in the prevalence of obesity and other diet-related disorders, including type 2 diabetes, hypertension and $\mathrm{CVD}^{(1-3)}$. Blood lipid levels play a causal role in the development of CVD. A meta-analysis has shown that LDL-cholesterol (LDL-C) and HDL-cholesterol (HDL-C) are independently associated with CVD risk ${ }^{(4)}$. Moreover, there is evidence that an increase in blood TAG concentration is also an independent risk factor for $\mathrm{CVD}^{(5)}$. Further, there exists strong evidence to suggest that plasma lipid response to dietary fat content is, to a large extent, genetically controlled $^{(6)}$. Thus, common genetic polymorphisms may render an individual more or less responsive to changes in dietary fat intake. Moreover, an individual's response to dietary fat is probably due to a combination of polymorphisms from various genes rather than a single polymorphism ${ }^{(6)}$. Overall, gene-diet interactions may provide important insights into the inter-individual variability observed in plasma lipid levels and thus on the risk of CVD.

The genetic background of the Inuit population has also been shown in previous studies to be protective; however, others have reported potentially detrimental effects for CVD susceptibility ${ }^{(7,8)}$. The interactions between polymorphisms, dietary fat intake and plasma lipid levels in the Inuit population may thus be different from those previously observed in other populations. Therefore, the main objective of the present study was to examine the associations between thirty-five known polymorphisms (SNP) in twenty candidate genes related to lipid metabolism, the intake of total fat (TotFat) or saturated fat (SatFat), and plasma lipid levels (total cholesterol (TC), LDL-C, HDL-C and TAG) in the Inuit population.

Abbreviations: HDL-C, HDL-cholesterol; LDL-C, LDL-cholesterol; SatFat, saturated fat; TC, total cholesterol; TotFat, total fat.

*Corresponding author: M.-C. Vohl, fax +1 418656 5877, email marie-claude.vohl@fsaa.ulaval.ca 


\section{Subjects and methods}

Subjects

Data were collected in the framework of the Nunavik Inuit Health Survey 'Qanuippitaa? How are we?' conducted among the Inuit of Nunavik in 2004. The survey covered all fourteen Nunavik communities. In the winter of 2009, participants from the Qanuippitaa Nunavik Health Survey in 2004 were revisited for the additional genetic component. The present study was conducted according to the guidelines laid down in the Declaration of Helsinki and all procedures involving human subjects were approved by the Ethics Committee on Research of Laval University and the Québec Public Health Ethics review board. Written informed consent was obtained from all subjects.

\section{Anthropometric measurements}

Height was measured using a rigid square and a measuring tape in a standardised standing position, with the participant's back against the wall looking straight ahead, with arms hanging down freely. Body weight was measured with a scale (Tanita TBF-300; Tanita Corporation). BMI was calculated as body weight $(\mathrm{kg}) /$ height $\left(\mathrm{m}^{2}\right)$, and internationally recommended cut-offs were used ${ }^{(9)}$.

\section{FFQ}

A validated $\mathrm{FFQ}^{(10)}$ was administered to the participants. The FFQ covered sixty-nine food items and beverages. Foods were divided into two major groups. The first group, 'country foods', refers to food items derived from fishing, hunting and gathering, recorded for each of the four seasons of the year before the interview. The second group, 'store-bought foods', refers to most store-bought foods imported from southern regions and consumed during the month before the survey. Pre-defined serving sizes were included in the questionnaire and a corresponding food model was shown to the respondents. Analysis of the FFQ data provided estimates of consumption frequency and the usual intake in grams of country foods on a daily, weekly, monthly, seasonal or an annual basis. Daily food intakes were calculated on an annual basis by multiplying food consumption frequency by intake in grams for each food.

\section{Plasma blood sampling}

Blood samples were collected from an antecubital vein into vacutainer tubes containing EDTA. Plasma was separated by centrifugation $\left(2500 \mathrm{~g}\right.$ for $10 \mathrm{~min}$ at $4^{\circ} \mathrm{C}$ ) and samples were portioned and frozen for subsequent measurements. Plasma TC and TAG levels were determined using enzymatic methods using a Hitachi 917 autoanalyser and reagents from Roche Diagnostics $^{(11,12)}$. The HDL-C fraction was obtained directly by selectively inhibiting the reaction with other lipoproteins. LDL-C was calculated with the Friedewald formula ${ }^{(13)}$. apoB and apoA1 concentrations and lipoprotein fractions were measured in plasma by the rocket immunoelectrophoretic method of Laurell ${ }^{(14)}$. Lipid analyses were performed at the Centre de Recherche sur les Maladies Lipidiques (Centre de Recherche du CHUQ, Quebec, QC, Canada).

\section{DNA extraction and genotyping}

DNA was extracted from $100 \mu$ l of buffy coat using the QIAamp 96 DNA Blood Kit (Qiagen, Inc.). The Quant-iT PicoGreen ${ }^{\circledR}$ dsDNA Assay Kit (Invitrogen) was used to quantify DNA. DNA was analysed with TaqMan ${ }^{\circledR}$ Pre-Designed SNP Genotyping Assays according to the manufacturer's instructions at the McGill University/Génome Québec Innovation Center (Montreal, Canada).

From a literature review, thirty-five polymorphisms in twenty genes relating to lipid metabolism were identified, namely: angiotensin I-converting enzyme (ACE) I/D alleles (rs4343), rs4341; angiotensinogen ( $A G T$ ) M235T (rs699), T174M (rs4762), A-20C (rs5050), A-6G (rs5051); apoA-I (APOA1) G-75A (rs670), 84T/C (rs5070); apoA-IV ( $A P O A 4)$ Asn147Ser (rs5104); apoA-V (APOA5) T-1131C (rs662799), $-3 \mathrm{~A} / \mathrm{G}$ (rs651821), S19W (rs3135506), Gly185Cys (rs2075291); apoB ( $A P O B)$ XbaI (rs693); apoC-III (APOC3) 3238C $>\mathrm{G}$ (rs5128), T-455C (rs2854116); apoE ( $A P O E)$ Cys112Arg (rs429358), Arg158Cys (rs7412), G-219T (rs405509); ATP-binding cassette, subfamily A ( $A B C 1)$, member 1 ( $A B C 1 A)$ Arg219Lys (rs2230806); cholesteryl ester transfer protein (CETP) TaqIB (rs708272), C-629A (rs1800775), C-4502T (rs183130), G-971A (rs4783961), Ile405Val (rs5882); cytochrome P450, family 1, subfamily A, polypeptide 1 (CYP1A1) Msp1 (rs4646903), A4889G (rs1048943); fat mass and obesity associated (FTO) rs9939609; glucokinase (hexokinase 4) regulator (GCKR) rs780094; insulin-induced gene 2 (INSIG2) rs7566605; lipoprotein lipase ( $L P L)$ HindIII (rs320), Ser447Ter (rs328); hepatic lipase (HL or LIPC) C-514T (rs1800588), G-250A (rs2070895); methylenetetrahydrofolate reductase $(N A D(P) H)$ (MTHFR) C677T (rs1801133); paraoxonase 1 (PON1) L55M (rs854560), Gln192Arg (rs662), C-107T (rs705379); PPPAR 2 (PPARG2) Pro12Ala (rs1801282), -681C/G (rs10865710); transcription factor 7-like 2 (TCF7L2) C47833T (rs7903146).

\section{Statistical analysis}

Hardy-Weinberg equilibrium was tested with the Allele Procedure in SAS, version 9.2 (SAS Institute, Inc.). Distribution of alleles was compared between the Inuit and Caucasian populations using the CEU data from the National Center for Biotechnology Information (NCBI; www.ncbi.nlm.nih.gov/) and analysed using the Fisher exact test.

Data are presented as means with their standard errors. Further, variables were checked for normality of distribution using skewness and the kurtosis values. TAG levels were log-transformed before analyses to normalise their distribution. A regression model was used to evaluate the effect of each polymorphism, the fat intake (either TotFat or SatFat as a continuous variable) and the polymorphism $\times$ fat intake interaction effect, adjusted for the effects of age, sex and BMI on each of the lipid variables. Second, a regression model adjusted for the effects of age, sex, BMI as well as 
energy intake was carried out on each of the lipid variables. Then, the regression $\beta$-coefficient $(\beta)$ was derived to estimate the phenotypic difference imparted by each of the genotype $\times$ fat intake interaction effects. In addition, to test for the additive effects of multiple polymorphisms, a 'risk score' was calculated based on the number of risk genotypes an individual carried from all the significant polymorphism $\times$ fat intake interactions for each lipid parameter. A statistical model was used to evaluate the effect of the 'risk score', fat intake (either TotFat or SatFat as a continuous variable) and the risk score $\times$ fat intake interaction effect, adjusted for the effects of age, sex and BMI on each of the lipid variables. Again, the regression $\beta$ was calculated to estimate the phenotypic difference contributed by the number of risk genotypes and fat intake interaction effects. Statistical analyses were performed with SAS statistical software, version 9.2 (SAS Institute, Inc.). Statistical significance was defined as $P \leq 0 \cdot 05$.

Results

\section{Subject characteristics}

In total, 677 households were contacted, of which 521 agreed to participate including 1056 individuals who signed a consent form and 917 who agreed to the collection of blood samples. In addition, 769 participants completed the FFQ. For the additional genetic component, 658 of the original participants gave consent. Consequently, statistical analyses were done for all individuals where plasma lipid levels, nutritional intake and genotypes were available. Therefore, 553 participants, including 251 men and 302 women, with an average age of 37 (SEM $0 \cdot 8)$ years and with an average BMI of $28(\operatorname{sem} 0.3) \mathrm{kg} / \mathrm{m}^{2}$ were included. Collectively, the Inuit population had a relatively favourable plasma lipid profile (Table 1) compared with an optimal profile ${ }^{(15)}$. Comprehensive results from blood lipid

Table 1. Baseline characteristics of the study subjects

(Mean values with their standard errors)

\begin{tabular}{|c|c|c|c|c|}
\hline & \multicolumn{2}{|c|}{ Men $(n 251)$} & \multicolumn{2}{|c|}{ Women (n 302) } \\
\hline & Mean & SEM & Mean & SEM \\
\hline \multicolumn{5}{|l|}{ Anthropometrics } \\
\hline Age (years) & $37 \cdot 1$ & 0.9 & $37 \cdot 3$ & 0.8 \\
\hline Weight $(\mathrm{kg})$ & 74.5 & 1.0 & $65 \cdot 9$ & 0.9 \\
\hline Height $(\mathrm{cm})$ & $165 \cdot 8$ & 0.4 & $154 \cdot 0$ & 0.3 \\
\hline BMI $\left(\mathrm{kg} / \mathrm{m}^{2}\right)$ & 27 & 0.3 & 28 & 0.4 \\
\hline \multicolumn{5}{|l|}{ Hypercholesterolaemia } \\
\hline$n$ & \multicolumn{2}{|c|}{22} & \multicolumn{2}{|c|}{21} \\
\hline$\%$ & \multicolumn{2}{|c|}{9} & \multicolumn{2}{|c|}{7} \\
\hline \multicolumn{5}{|l|}{ Plasma lipids } \\
\hline Total cholesterol $(\mathrm{mmol} / \mathrm{l})$ & 4.94 & 0.06 & 5.04 & 0.05 \\
\hline HDL-cholesterol (mmol//) & 1.48 & 0.02 & 1.79 & 0.03 \\
\hline LDL-cholesterol (mmol/l) & $2 \cdot 89$ & 0.06 & $2 \cdot 74$ & 0.05 \\
\hline Total:HDL-cholesterol & 3.52 & 0.07 & 2.96 & 0.05 \\
\hline TAG $(\mathrm{mmol} / \mathrm{l})$ & 1.25 & 0.04 & $1 \cdot 11$ & 0.04 \\
\hline apoB100 (mmol/l) & 0.97 & 0.02 & 0.93 & 0.01 \\
\hline apoA1 (mmol/l) & 1.62 & 0.02 & $1 \cdot 77$ & 0.02 \\
\hline \multicolumn{5}{|l|}{ Daily intake } \\
\hline Total energy intake (kJ) & 10932 & 352 & 9291 & 301 \\
\hline Total fat intake $(\mathrm{g})$ & $76 \cdot 1$ & $2 \cdot 7$ & 63.4 & $2 \cdot 5$ \\
\hline Total saturated fat intake $(\mathrm{g})$ & $27 \cdot 2$ & 1.0 & $22 \cdot 2$ & 0.9 \\
\hline
\end{tabular}

levels in the whole Inuit population have been published previously $^{(1)}$. Further, FFQ data demonstrate that the average total dietary fat intake was 76 and $63 \mathrm{~g} / \mathrm{d}$ (approximately $26 \%$ of energy intake per d) in men and women, respectively, including 27 and $22 \mathrm{~g} / \mathrm{d}$ of SatFat (approximately 9\% of energy intake per d) in men and women, respectively, for this particular subset of the population.

\section{Genotypic characteristics}

Genotype frequencies did not deviate from those predicted by the Hardy-Weinberg equilibrium except for the following three SNP: $L P L$ HindIII (rs320), LPL Ser447Ter (rs328) and TCF7L2 C47833T (rs7903146), which were excluded from the statistical analyses. The minor alleles of the SNP $A G T$ T174M (rs4762), AGT A-20C (rs5050), APOA5 Gly185Cys (rs2075291), APOA5 S19W (rs3135506), APOE Cys112Arg (rs429358), FTO (rs9939609) and TCF7L2 C47833T (rs7903146) had low frequencies $(<0 \cdot 10)$ in the Inuit population and were also excluded from the analyses.

In addition, allele frequencies were significantly different $(P<0.05)$ in the Inuit population compared with the Caucasian population for the following eighteen SNP: $A B C 1 A$ Arg219Lys (rs2230806); AGT M235T (rs699); APOA1 G-75A (rs670); APOA4 Asn147Ser (rs5104); $A P O A 5 \quad-3 \mathrm{~A} / \mathrm{G}$ (rs651821); $A P O A 5$ T-1131C (rs662799); $A P O B$ XbaI (rs693); $A P O C 3$ 3238C $>\mathrm{G}$ (rs5128); $A P O E$ G-219T (rs405509); $A P O E$ Cys112Arg (rs429358); CETP TaqIB (rs708272); CETP C-629A (rs1800775); CYP1A1 A4889G (rs1048943); FTO (rs9939609); MTHFR C677T (rs1801133); PON1 L55M (rs854560); PPARG2 -681C/G (rs10865710); TCF7L2 C47833T (rs7903146) (see Supplementary material 1 , available online).

\section{Gene-diet interaction in plasma lipid levels}

A total of fourteen interactions between SNP and TotFat intake were observed. Individuals with the $\mathrm{T} / \mathrm{T}$ genotype of $A G T$ M235T (rs699), the T/T genotype of CETP Ile405Val (rs5882), the $\mathrm{G}$ allele of $C Y P 1 A 1$ A4889G (rs1048943), the $\mathrm{C}$ allele of $P P A R G 2-681 \mathrm{C} / \mathrm{G}$ (rs10856710) and the $\mathrm{T}$ allele of $A P O B$ XbaI (rs693) increased their TC to a greater extent than the other genotype groups with higher TotFat intake (Table 2). Similarly, higher LDL-C levels were associated with a higher dietary TotFat in individuals bearing the $\mathrm{T} / \mathrm{T}$ genotype of $A G T \mathrm{M} 235 \mathrm{~T}$ (rs699), the $\mathrm{T} / \mathrm{T}$ genotype of $A P O E$ G-219T (rs405509), the $\mathrm{G}$ allele of $A P O A 1 \mathrm{G}-75 \mathrm{~A}$ (rs670), the C allele of $A P O C 3 \quad 3238 \mathrm{C}>\mathrm{G}$ (rs5128), the $\mathrm{C}$ allele of PPARG2 - 681C/G (rs10856710) and the $\mathrm{T}$ allele of $A P O B$ XbaI (rs693) (Table 3). Further, lower HDL-C levels were related to a higher TotFat intake in carriers of the $\mathrm{C} / \mathrm{C}$ genotype of $A P O A 184 \mathrm{~T} / \mathrm{C}$ (rs5070) and the $\mathrm{T} / \mathrm{T}$ genotype of $A P O E$ G-219T (rs405509) (Table 4). Carriers of the T/T genotype of LIPC C-514T (rs1800588) had higher TAG levels with a higher TotFat intake (Table 5). The same SNP $\times$ TotFat interactions were seen when energy intake was included in the regression model, in addition to age, sex and BMI (data not shown). In addition, a higher number of these aforementioned risk alleles and higher TotFat intake were associated with 
Table 2. Impact of SNP, dietary fat intake and the interaction SNP $\times$ dietary fat intake on total cholesterol levels* ( $\beta$ Coefficients with their standard errors)

\begin{tabular}{|c|c|c|c|c|c|c|c|c|}
\hline \multirow[b]{2}{*}{ SNP } & \multirow[b]{2}{*}{ Genotype } & \multirow[b]{2}{*}{$n$} & \multicolumn{3}{|c|}{ Total fat } & \multicolumn{3}{|c|}{ Saturated fat } \\
\hline & & & $\beta \dagger$ & SEM & $\begin{array}{l}P \text { for interaction } \\
\text { effect } \ddagger\end{array}$ & $\beta \dagger$ & SEM & $\begin{array}{l}P \text { for interaction } \\
\text { effect }\end{array}$ \\
\hline \multirow[t]{3}{*}{ APOA1 G-75A (rs670)§ } & $\mathrm{G} / \mathrm{G}$ & 382 & & & NS & $0^{\mathrm{a}}$ & & 0.0221 \\
\hline & $\mathrm{G} / \mathrm{A}$ & 149 & & & & $0.0158^{\mathrm{b}}$ & 0.0102 & \\
\hline & $\mathrm{A} / \mathrm{A}$ & 22 & & & & $0.0012^{\mathrm{a}}$ & 0.0057 & \\
\hline \multirow[t]{3}{*}{$A P O B \mathrm{Xbal}(\mathrm{rs} 693) \S$} & $\mathrm{C} / \mathrm{C}$ & 360 & $0^{\mathrm{a}}$ & & 0.0243 & $0^{\mathrm{a}}$ & & 0.0066 \\
\hline & $\mathrm{C} / \mathrm{T}$ & 171 & $0.0043^{b}$ & 0.0019 & & $0.0126^{b}$ & 0.0052 & \\
\hline & $\mathrm{T} / \mathrm{T}$ & 22 & $0.0096^{b}$ & 0.0039 & & $0.0246^{b}$ & 0.0010 & \\
\hline \multirow[t]{3}{*}{ CETP lle405Val (rs5882) } & $\mathrm{C} / \mathrm{C}$ & 144 & $0^{a, b}$ & & 0.0460 & & & NS \\
\hline & $\mathrm{C} / \mathrm{T}$ & 265 & $-0.0029^{a}$ & 0.0023 & & & & \\
\hline & $\mathrm{T} / \mathrm{T}$ & 144 & $0.0024^{\mathrm{b}}$ & 0.0026 & & & & \\
\hline \multirow[t]{3}{*}{ CYP1A1 A4889G (rs1048943)§ } & $\mathrm{A} / \mathrm{A}$ & 166 & $0^{\mathrm{a}}$ & & 0.0332 & & & NS \\
\hline & $A / G$ & 271 & $0.0031^{a, b}$ & 0.0020 & & & & \\
\hline & $\mathrm{G} / \mathrm{G}$ & 116 & $0.0061^{b}$ & 0.0024 & & & & \\
\hline \multirow[t]{3}{*}{ AGT M235T (rs699)§ } & $\mathrm{C} / \mathrm{C}$ & 392 & $0^{a, b}$ & & 0.0062 & $0^{a, b}$ & & 0.0022 \\
\hline & $\mathrm{C} / \mathrm{T}$ & 144 & $-0.0054^{a}$ & 0.0021 & & $-0.0151^{a}$ & 0.0151 & \\
\hline & $\mathrm{T} / \mathrm{T}$ & 17 & $0.0097^{\mathrm{b}}$ & 0.0060 & & $0.0248^{\mathrm{b}}$ & 0.0126 & \\
\hline \multirow[t]{3}{*}{ PPARG2 - 681C/G (rs10865710)§ } & $\mathrm{C} / \mathrm{C}$ & 177 & $0.0069^{b}$ & 0.0025 & 0.0175 & $0.0195^{\mathrm{b}}$ & 0.0067 & 0.0159 \\
\hline & $\mathrm{C} / \mathrm{G}$ & 254 & $0.0053^{b}$ & 0.0023 & & $0.0132^{b}$ & 0.0064 & \\
\hline & $\mathrm{G} / \mathrm{G}$ & 122 & $0^{\mathrm{a}}$ & & & $0^{\mathrm{a}}$ & & \\
\hline
\end{tabular}

${ }^{\mathrm{a}, \mathrm{b}} \beta$ Coefficients with unlike superscript letters for one SNP were significantly different.

* The model includes SNP, fat intake and the interaction term (SNP $\times$ fat intake) with adjustment for the effects of age, sex and BMI.

$\dagger$ The $\beta$ regression coefficients are derived from absolute values.

$\ddagger P$ values are calculated with normalised values.

$\S$ Genotype frequency is different between the Inuit and Caucasian populations.

significantly higher TC, LDL-C or TAG levels, as well as with lower HDL-C levels (Figs. 1-3).

Similarly, thirteen interactions between SNP and SatFat intake were observed. The pattern of association with SatFat intake was similar to the pattern obtained with TotFat intake (eleven out of fourteen interactions); however, there were a few differences. The individuals with the $\mathrm{T} / \mathrm{T}$ genotype of $A G T$ M235T (rs699), the C allele of PPARG2 - 681C/G (rs10856710) and the $\mathrm{T}$ allele of $A P O B$ XbaI (rs693) had higher TC levels with a higher SatFat intake (Table 2). In addition, APOA1 G-75A (rs670) SNP and SatFat determined the TC levels (Table 2). Similarly (except for one SNP),

Table 3. Impact of SNP, dietary fat intake and the interaction SNP $\times$ dietary fat intake on plasma LDL-cholesterol levels*

( $\beta$ Coefficients with their standard errors)

\begin{tabular}{|c|c|c|c|c|c|c|c|c|}
\hline \multirow[b]{2}{*}{ SNP } & \multirow[b]{2}{*}{ Genotype } & \multirow[b]{2}{*}{$n$} & \multicolumn{3}{|c|}{ Total fat } & \multicolumn{3}{|c|}{ Saturated fat } \\
\hline & & & $\beta \dagger$ & SEM & $\begin{array}{l}P \text { for interaction } \\
\text { effect } \ddagger\end{array}$ & $\beta \dagger$ & SEM & $\begin{array}{c}P \text { for interaction } \\
\text { effect } \ddagger\end{array}$ \\
\hline \multirow[t]{3}{*}{ APOA1 G-75A (rs670)§ } & $\mathrm{G} / \mathrm{G}$ & 382 & $0.0018^{a, b}$ & 0.0034 & 0.028 & $0.0015^{\mathrm{a}, \mathrm{b}}$ & 0.0093 & 0.0299 \\
\hline & $\mathrm{G} / \mathrm{A}$ & 149 & $0.0065^{b}$ & 0.0036 & & $0.0150^{\mathrm{b}}$ & 0.0099 & \\
\hline & $\mathrm{A} / \mathrm{A}$ & 22 & $0^{a}$ & & & $0^{a}$ & & \\
\hline \multirow[t]{3}{*}{$A P O B \mathrm{Xbal}(\mathrm{rs} 693) \S$} & $\mathrm{C} / \mathrm{C}$ & 360 & $0^{a}$ & & 0.0243 & $0^{a}$ & & 0.0128 \\
\hline & $\mathrm{C} / \mathrm{T}$ & 171 & $0.0025^{a, b}$ & 0.0017 & & $0.0083^{a, b}$ & 0.0090 & \\
\hline & $\mathrm{T} / \mathrm{T}$ & 22 & $0.0089^{b}$ & 0.0035 & & $0.0240^{b}$ & 0.0047 & \\
\hline \multirow[t]{3}{*}{ APOE G-219T (rs405509)§ } & $\mathrm{T} / \mathrm{T}$ & 254 & $0.0034^{b}$ & 0.0024 & 0.0228 & & & NS \\
\hline & $\mathrm{G} / \mathrm{T}$ & 249 & $-0.0014^{a, b}$ & 0.0024 & & & & \\
\hline & $\mathrm{G} / \mathrm{G}$ & 50 & $0^{a}$ & & & & & \\
\hline \multirow[t]{3}{*}{ APOC3 $3238 \mathrm{C}>\mathrm{G}(\mathrm{rs} 5128) \S$} & $\mathrm{C} / \mathrm{C}$ & 183 & $0.0054^{b}$ & 0.0023 & 0.0366 & $0.0154^{b}$ & 0.0061 & 0.0313 \\
\hline & $\mathrm{C} / \mathrm{G}$ & 254 & $0.0048^{b}$ & 0.0021 & & $0.0128^{b}$ & 0.0057 & \\
\hline & $\mathrm{G} / \mathrm{G}$ & 116 & $0^{\mathrm{a}}$ & & & $0^{a}$ & & \\
\hline \multirow[t]{3}{*}{ AGT M235T (rs699)§ } & $\mathrm{C} / \mathrm{C}$ & 392 & $0^{a, b}$ & & 0.0149 & $0^{a, b}$ & & 0.0037 \\
\hline & $\mathrm{C} / \mathrm{T}$ & 144 & $-0.0046^{a}$ & 0.0019 & & $-0.0137^{a}$ & 0.0051 & \\
\hline & $\mathrm{T} / \mathrm{T}$ & 17 & $0.0072^{b}$ & 0.0054 & & $0.0197^{b}$ & 0.0114 & \\
\hline \multirow[t]{3}{*}{ PPARG2 - 681C/G (rs10865710)§ } & $\mathrm{C} / \mathrm{C}$ & 177 & $0.0068^{b}$ & 0.0022 & 0.0070 & $0.0186^{b}$ & 0.0061 & 0.0087 \\
\hline & $\mathrm{C} / \mathrm{G}$ & 254 & $0.0054^{b}$ & 0.0021 & & $0.0134^{b}$ & 0.0058 & \\
\hline & $\mathrm{G} / \mathrm{G}$ & 122 & $0^{\mathrm{a}}$ & & & $0^{a}$ & & \\
\hline
\end{tabular}

${ }^{\mathrm{a}, \mathrm{b}} \beta$ Coefficients with unlike superscript letters for one SNP were significantly different.

* The model includes SNP, fat intake, and the interaction term (SNP $\times$ fat intake) with adjustment for the effects of age, sex and BMI.

$\dagger$ The $\beta$ regression coefficients are derived from absolute values.

$\ddagger P$ values are calculated with normalised values.

$\S$ Genotype frequency is different between the Inuit and Caucasian populations. 
Table 4. Impact of SNP, dietary fat intake and the interaction SNP $\times$ dietary fat intake on plasma HDL-cholesterol levels*

( $\beta$ Coefficients with their standard errors)

\begin{tabular}{|c|c|c|c|c|c|c|c|c|}
\hline \multirow[b]{2}{*}{ SNP } & \multirow[b]{2}{*}{ Genotype } & \multirow[b]{2}{*}{$n$} & \multicolumn{3}{|c|}{ Total fat } & \multicolumn{3}{|c|}{ Saturated fat } \\
\hline & & & $\beta \dagger$ & SEM & $P$ for interaction effect $\ddagger$ & $\beta \dagger$ & SEM & $P$ for interaction effect $\ddagger$ \\
\hline \multirow[t]{3}{*}{ APOA1 84T/C (rs5070) } & $\mathrm{T} / \mathrm{T}$ & 221 & $0^{a}$ & & \multirow[t]{3}{*}{0.0318} & $0^{\mathrm{a}}$ & & \multirow[t]{3}{*}{0.0148} \\
\hline & $T / C$ & 254 & $-0.0001^{a}$ & 0.0008 & & $0.0004^{\mathrm{a}}$ & 0.0035 & \\
\hline & $\mathrm{C} / \mathrm{C}$ & 78 & $-0.0031^{b}$ & 0.0012 & & $-0.0092^{b}$ & 0.0021 & \\
\hline \multirow{3}{*}{ APOE G-219T (rs405509)§ } & $T / T$ & 254 & $-0.0010^{b}$ & 0.0011 & \multirow[t]{3}{*}{0.0486} & $-0.0027^{b}$ & 0.0032 & \multirow[t]{3}{*}{0.0129} \\
\hline & $\mathrm{G} / \mathrm{T}$ & 249 & $0.0011^{a}$ & 0.0011 & & $0.0038^{a}$ & 0.0032 & \\
\hline & $G / G$ & 50 & $0^{a, b}$ & & & $0^{\mathrm{a}, \mathrm{b}}$ & & \\
\hline
\end{tabular}

${ }^{\mathrm{a}, \mathrm{b}} \beta$ Coefficients with unlike superscript letters for one SNP were significantly different.

* The model includes SNP, fat intake and the interaction term (SNP $\times$ fat intake) with adjustment for the effects of age, sex and BMI.

$\dagger$ The $\beta$ regression coefficients are derived from absolute values.

$\ddagger P$ values are calculated with normalised values.

$\S$ Genotype frequency is different between the Inuit and Caucasian populations.

higher LDL-C levels were associated with a higher SatFat intake for the T/T genotype of $A G T \mathrm{M} 235 \mathrm{~T}$ (rs699), the $\mathrm{G}$ allele of $A P O A 1 \mathrm{G}-75 \mathrm{~A}$ (rs670), the $\mathrm{C}$ allele of $A P O C 3 \quad 3238 \mathrm{C}>\mathrm{G}$ (rs5128), the $\mathrm{C}$ allele of PPARG2 -681C/G (rs10865710) and the $\mathrm{T}$ allele of $A P O B$ XbaI (rs693) (Table 3). Lower HDL-C levels were associated with a higher SatFat intake for individuals with the C/C genotype of $A P O A 184 \mathrm{~T} / \mathrm{C}$ (rs5070) and the T/T genotype of $A P O E$ G-219T (rs405509) (Table 4). Higher TAG levels were associated with a higher SatFat intake in carriers of the T/T genotype of LIPC C-514T (rs1800588) as well as the C/C genotype of ABCA1 Arg219Lys (rs2230806) (Table 5). Again, the same SNP $\times$ SatFat interactions were seen when energy intake was included in the model, in addition to age, sex and BMI (data not shown). Similarly to the SNP $\times$ TotFat data, a higher number of these aforementioned risk alleles and higher SatFat intake were associated with significantly higher TC, LDL-C and TAG levels, as well as with lower HDL-C levels (data not shown).

Similar statistical analyses were done with apoB100 (apoB) and apoA1 levels, which yielded the same interaction results as seen for LDL-C and HDL-C levels, respectively (data not shown).

\section{Discussion}

The present study confirms that there are genetic differences between the Inuit and Caucasian populations; even so, interactions between polymorphisms, dietary fat intake and plasma lipid levels also exist in the Inuit population. More specifically, seven SNP, namely $A P O B$ XbAI (rs693), APOA1 - 75G/A (rs670), APOE 219G/T (rs405509), LIPC 480C/T (rs1800588), $A G T \mathrm{M} 235 \mathrm{~T}$ (rs699), APOA1 84T/C (rs5070) and PPARG2 -618C/G (rs10865710), in interaction with TotFat and SatFat intake were associated with plasma levels of at least one of the following risk factors for CVD: TC, HDL-C, LDL-C and TAG.

Participants who had the minor allele of $A P O B$ XbAI (rs693) demonstrated higher plasma TC and LDL-C levels when consuming a high TotFat and SatFat diet. Numerous studies have previously demonstrated that carriers of the minor allele had elevated LDL-C levels and a less pronounced plasma lipid response to changes in dietary fat intake ${ }^{(16-22)}$. Thus, individuals who carry the minor allele for rs693 in the $A P O B$ gene combined with a higher dietary fat intake may be at risk of hypercholesterolaemia.

Similarly, higher TotFat and SatFat intakes were associated with higher plasma LDL-C levels, as well a higher SatFat intake was associated with higher plasma TC, in heterozygotes for $A P O A 1-75 \mathrm{G} / \mathrm{A}$ (rs670). A previous study showed that subjects carrying the mutated allele had higher TC, LDL-C and TAG levels than homozygotes for the wild-type allele $^{(23)}$. In addition, a diet rich in PUFA has been shown to induce greater plasma TC and LDL-C decreases in heterozygotes than in wild-type subjects compared with a high-SatFat

Table 5. Impact of SNP, dietary fat intake and the interaction SNP $\times$ dietary fat intake on plasma TAG levels*

( $\beta$ Coefficients with their standard errors)

\begin{tabular}{|c|c|c|c|c|c|c|c|c|}
\hline \multirow[b]{2}{*}{ SNP } & \multirow[b]{2}{*}{ Genotype } & \multirow[b]{2}{*}{$n$} & \multicolumn{3}{|c|}{ Total fat } & \multicolumn{3}{|c|}{ Saturated fat } \\
\hline & & & $\beta \dagger$ & SEM & $\begin{array}{l}P \text { for interaction } \\
\text { effect }\end{array}$ & $\beta \dagger$ & SEM & $\begin{array}{l}P \text { for interaction } \\
\text { effect }\end{array}$ \\
\hline LIPC C-514T (rs1800588) & $\begin{array}{l}\mathrm{T} / \mathrm{T} \\
\mathrm{C} / \mathrm{T} \\
\mathrm{C} / \mathrm{C}\end{array}$ & $\begin{array}{c}55 \\
244 \\
254\end{array}$ & $\begin{array}{c}0.0046^{\mathrm{b}} \\
-0.0082^{\mathrm{a}} \\
0^{\mathrm{a}, \mathrm{b}}\end{array}$ & $\begin{array}{l}0.0024 \\
0.0013\end{array}$ & 0.0298 & $\begin{array}{c}0.0126^{\mathrm{b}} \\
-0.0047^{\mathrm{a}} \\
0^{\mathrm{a}, \mathrm{b}}\end{array}$ & $\begin{array}{l}0.0064 \\
0.0034\end{array}$ & 0.0316 \\
\hline$A B C A 1$ Arg219Lys (rs2230806)§ & $\begin{array}{l}\mathrm{C} / \mathrm{C} \\
\mathrm{C} / \mathrm{T} \\
\mathrm{T} / \mathrm{T}\end{array}$ & $\begin{array}{c}227 \\
260 \\
66\end{array}$ & NS & NS & NS & $\begin{array}{c}0.0089^{\mathrm{b}} \\
0.0004^{\mathrm{a}, \mathrm{b}} \\
0^{\mathrm{a}}\end{array}$ & $\begin{array}{l}0.0057 \\
0.0053\end{array}$ & 0.0433 \\
\hline
\end{tabular}

${ }^{\mathrm{a}, \mathrm{b}} \beta$ Coefficients with unlike superscript letters for one SNP were significantly different.

* The model includes SNP, fat intake and the interaction term (SNP $\times$ fat intake) with adjustment for the effects of age, sex and BMI.

$\dagger$ The $\beta$ regression coefficients are derived from absolute values.

$\ddagger P$ values are calculated with normalised values.

$\S$ Genotype frequency is different between the Inuit and Caucasian populations. 


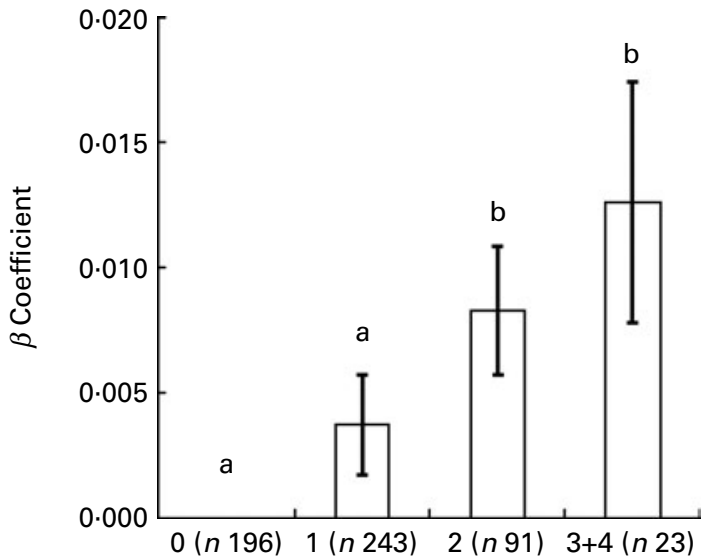

Fig. 1. Effects of multiple significant SNP (taken from Table 2) as a 'risk score' in interaction with total fat on total cholesterol levels. Values are means, with their standard errors represented by vertical bars. ${ }^{a, b}$ Mean values with unlike letters for 'at-risk' groups were significantly different $(P=0.0002)$.

diet $^{(23)}$. In contrast, an earlier study showed no differences between genotype groups for any lipid variables; yet, the $-75 \mathrm{G} / \mathrm{A}$ polymorphism appears to have an effect on plasma TC, LDL-C and HDL-C responsiveness to increased PUFA in the diet ${ }^{(24)}$. Further, the presence of the A allele has previously been associated with increased promoter activity in vitro ${ }^{(25)}$. Overall, studies have shown that the response to dietary fat intake may be modified by the $-75 \mathrm{G} / \mathrm{A}$ (rs670) mutation.

Moreover, in the present study, participants with the $\mathrm{T} / \mathrm{T}$ genotype of $A P O E$ 219G/T (rs405509) exhibited higher plasma LDL-C and lower plasma HDL-C levels when consuming a high-TotFat and -SatFat diet. Similarly, a study demonstrated that carriers of the $\mathrm{T}$ allele had higher LDL-C and apoB plasma levels after the SatFat diet compared with $G / G$ homozygotes $^{(26)}$. In addition, carriers of the $\mathrm{T}$ allele had a greater decrease in LDL-C and apoB levels when they modified their diet from a SatFat diet to a carbohydrate $\operatorname{diet}^{(26)}$. These results suggest that the 219G/T polymorphism may also partially explain inter-individual differences in plasma lipid response to dietary fat intake.

In the Inuit population, carriers of the minor allele of LIPC C-514T (rs1800588) had higher TAG levels when they consumed a high-TotFat and -SatFat diet. Fan et al. ${ }^{(27)}$ also showed that serum TC, HDL-C and TAG levels increased according to the rs1800588 genotype in the order $\mathrm{C} / \mathrm{C}$, $\mathrm{C} / \mathrm{T}$ and $\mathrm{T} / \mathrm{T}$ in the Finnish population. Further, studies have suggested that the effects of $\mathrm{C}-514 \mathrm{~T}$ polymorphism on HDL-C levels were modified by TotFat and SatFat intake ${ }^{(28-30)}$. Clearly, there exists a gene-diet interaction between plasma lipid levels, dietary fat intake and LIPC C-514T polymorphism.

Further, higher TotFat and SatFat intakes were related to higher TC and LDL-C in carriers of the minor allele of $A G T$ M235T (rs699). Previously, the M235T polymorphism (rs699) in the $A G T$ gene has been related to an increased risk of $\mathrm{CVD}^{(31)}$ via the presence of hypercholesterolaemia. Overall, these results for $A G T$ (rs699) are supported by previous

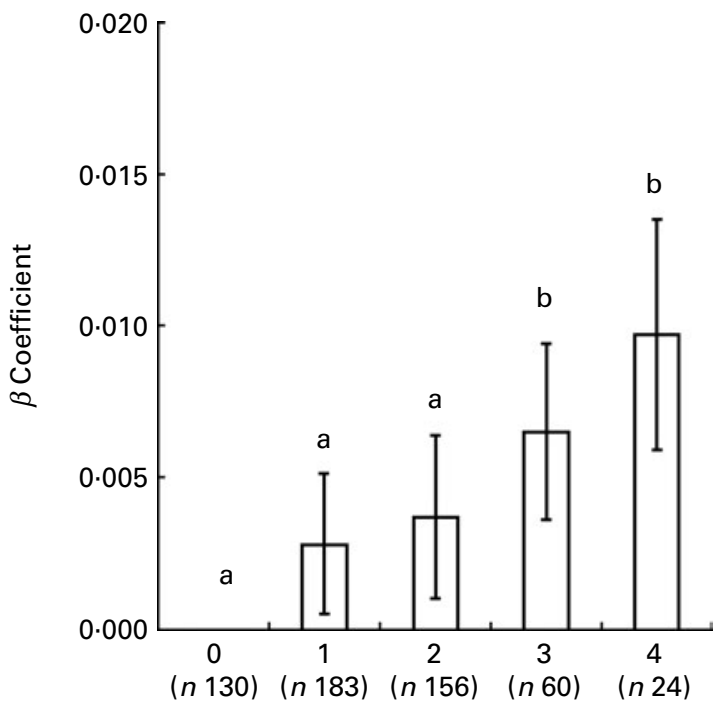

Fig. 2. Effects of multiple SNP (taken from Table 3) as a 'risk score' in interaction with total fat on LDL-cholesterol levels. Values are means, with their standard errors represented by vertical bars. ${ }^{a, b}$ Mean values with unlike letters for 'at-risk' groups were significantly different $(P=0.05)$.

epidemiological studies ${ }^{(31)}$; however, this gene-diet interaction should be reconfirmed.

In the Inuit population, two polymorphisms, namely APOA1 84T/C (rs5070) and PPARG2 - 618C/G (rs10865710), had opposite effects than described previously in epidemiological studies, which did not take dietary fat intake into consideration. First, carriers of the minor allele of $A P O A 184 \mathrm{~T} / \mathrm{C}$ (rs5070) had lower HDL-C levels with a higher TotFat or SatFat intake. In contrast, other studies have shown that the minor $\mathrm{C}$ allele was protective: higher HDL-C and lower TAG levels observed in the Japanese population ${ }^{(32,33)}$. Second, participants with the wild-type allele of PPARG2 -618C/G (rs10865710) had higher TC and LDL-C levels when consuming a higher-TotFat and -SatFat diet. Contrary to the present results, the carrier of the mutated allele of PPARG2

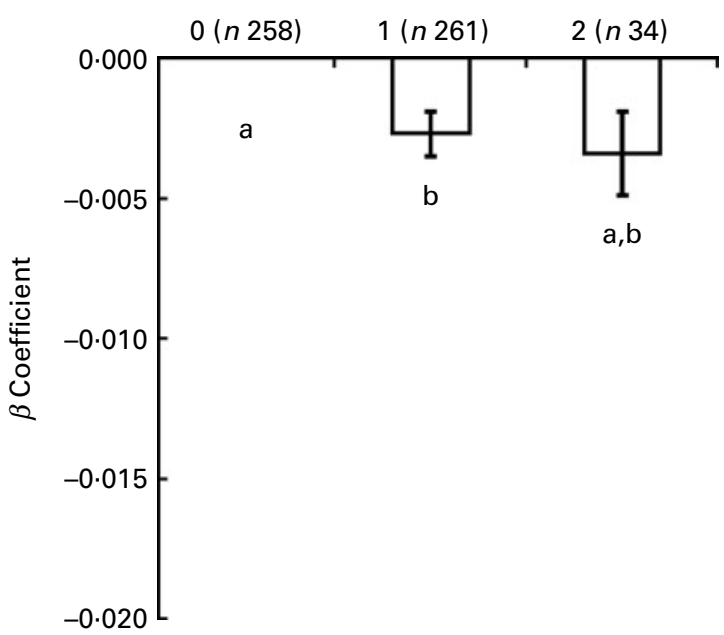

Fig. 3. Effects of multiple SNP (taken from Table 4) as a 'risk score' in interaction with total fat on HDL-cholesterol levels. Values are means, with their standard errors represented by vertical bars. ${ }^{a, b}$ Mean values with unlike letters for 'at-risk' groups were significantly different $(P=0.0014)$. 
- 618C/G was previously associated with a deteriorated lipid profile in a Caucasian population ${ }^{(34)}$. Thus, the addition of dietary fat intake with genetic variations may explain discrepancies in plasma lipids levels. In summary, these results suggest that the interaction with dietary fat may determine the risk allele with these two polymorphisms.

Additionally, four SNP, including APOC3 $3238 \mathrm{C}>\mathrm{G}$ (rs5128), CETP I405V (rs5882), CYP1A1 A4889G (rs1048943) and ABCA1 Arg219Lys (rs2230806), showed an interaction with either TotFat or SatFat intake to modulate one plasma lipid variable. A higher TotFat intake was associated with higher plasma LDL-C levels in individuals who carry the wild-type allele of APOC3 3238C > G (rs5128). Previously, the carrier of the mutated allele of $A P O C 33238 \mathrm{C}>\mathrm{G}$ has been associated with elevated plasma TC and TAG levels ${ }^{(35,36)}$. Lopez-Miranda et al. ${ }^{(37)}$ also demonstrated a decrease in plasma LDL-C concentration in heterozygous subjects after consumption of a diet high in MUFA compared with an increase in plasma LDL-C concentration in wild-type subjects. Additionally, carriers of the I405V (rs5882) polymorphism in the CETP gene had higher plasma TC levels when consuming a high-TotFat diet. Previously, Darabi et al. ${ }^{(38)}$ showed that subjects carrying the mutated allele had a greater reduction in plasma HDL-C levels without changes in TC compared with subjects with the other genotype after a diet low in PUFA:SatFat ratio ${ }^{(38)}$. Thus, these genetic variations may modulate the effect of dietary fat on blood lipids in the Inuit and other populations; yet, more studies are needed to validate these gene-diet interaction effects.

Furthermore, the CYP1A1 A4889G polymorphism (rs1048943) was associated with higher plasma TC levels with a higher TotFat intake. Studies have shown that CYP1A1 is involved in the bioactivation and detoxification of environmental toxins ${ }^{(39)}$. The biological significance of this interaction needs to be validated; however, it might be of interest to examine the interaction between polymorphisms, dietary fat intake and environmental toxins in the Inuit population as factors influencing plasma lipid levels.

A higher SatFat intake was related to higher plasma TAG levels in carriers of the $\mathrm{C}$ allele of ABCA1 Arg219Lys (rs2230806). Genetic variants of $A B C A 1$ have been associated with altered atherosclerosis progression and fasting lipid concentration; however, results from different studies have been inconsistent ${ }^{(40-42)}$. Therefore, the impact of this polymorphism may be altered by gene-diet interactions.

Further, a combination of SNP coupled with dietary fat intake generated additive effects on lipid traits, which increases the risk of CVD. Overall, these risk alleles in interaction with dietary fat intake, including TotFat and SatFat, may significantly influence the risk of CVD, especially when the risk allele is in a greater proportion in the Inuit population compared with the Caucasian population. Thus, these results suggest that the environment, such as dietary fat consumed, interacts with genes to produce phenotypic differences. Similar to previous reports ${ }^{(43)}$, each genetic variant had a small-tomoderate effect; however, the combined effect of all significant variants explained a modest extent of lipid variation.
In conclusion, the findings indicate that genetic variants involved in the modulation of lipid metabolism may play an important role in the modulation of cardiovascular health of the Inuit population. The inclusion of environmental factors, such as TotFat and SatFat, to the genetic association study can help to better predict inter-individual variations in plasma lipid levels. Yet, many other SNP exist in lipid metabolism that have not yet been examined. Further, the present study also supports the notion that the multiple-gene approach might provide a better prediction of lipid variations in the population, but this needs to be investigated in a largescale study. Overall, the assessment of gene-diet interactions may be a valuable tool to predict the impact of dietary changes on plasma lipid levels in order to reduce the risk of CVD.

\section{Acknowledgements}

We express our gratitude to the participants for their collaboration. This study was supported by the Ministère de la santé et des services sociaux du Québec, the Nunavik Regional Board of Health and Social Services, the Network of Centres of Excellence of Canada (ArcticNet), the Nasivvik Centre, the Nasivvik ACADRE Inuit Centre, Northern and Indian Affairs (Northern Contaminant Program) and the Canadian Institutes of Health Research (CIHR). I. R. was supported by a CIHR Bisby Postdoctoral Fellowship Award (200810BFE). Y. G. holds a senior research scholarship from the Fonds de la Recherche en Santé du Québec (FRSQ). M.-C. V. holds a Tier 1 Canada Research Chair in Genomics Applied to Nutrition and Health. The authors' contributions are as follows: I. R. performed the statistical analysis, interpreted the data and wrote the paper; V. B., A. D.-L., B. A., Y. G. and M.-L. C.-D. were responsible for the data collection and the analysis including genotyping, nutrient intakes and lipid parameters in the original study; E. D., R. A. H. and M.-C. V. were responsible for the study design; all authors contributed to the critical revision of the manuscript; I. R. and M.-C. V. had primary responsibility for the final content. All authors read and approved the final manuscript. The authors declare that there are no conflicts of interest.

Supplementary material is available online at http://www. journals.cambridge.org/bjn

\section{References}

1. Chateau-Degat ML, Dewailly E, Louchini R, et al. (2010) Cardiovascular burden and related risk factors among Nunavik (Quebec) Inuit: insights from baseline findings in the circumpolar Inuit health in transition cohort study. Can J Cardiol 26, 190-196.

2. Counil E, Julien P, Lamarche B, et al. (2009) Association between trans-fatty acids in erythrocytes and pro-atherogenic lipid profiles among Canadian Inuit of Nunavik: possible influences of sex and age. BrJ Nutr 102, 766-776.

3. Chateau-Degat ML, Dewailly E, Noel M, et al. (2010) Hypertension among the Inuit from Nunavik: should we expect an increase because of obesity? Int J Circumpolar Health 69 $361-372$. 
4. Lewington S, Whitlock G, Clarke R, et al. (2007) Blood cholesterol and vascular mortality by age, sex, and blood pressure: a meta-analysis of individual data from 61 prospective studies with 55,000 vascular deaths. Lancet 370, 1829-1839.

5. Bansal S, Buring JE, Rifai N, et al. (2007) Fasting compared with nonfasting triglycerides and risk of cardiovascular events in women. JAMA 298, 309-316.

6. Rudkowska I \& Vohl MC (2010) Interaction between diets, polymorphisms and plasma lipids levels. Clin Lipidol 5, 421-438.

7. Hegele RA, Young TK \& Connelly PW (1997) Are Canadian Inuit at increased genetic risk for coronary heart disease? J Mol Med 75, 364-370.

8. de Maat MP, Bladbjerg EM, Johansen LG, et al. (1999) DNApolymorphisms and plasma levels of vascular disease risk factors in Greenland Inuit - is there a relation with the low risk of cardiovascular disease in the Inuit? Thromb Haemost 81, 547-552.

9. Kuczmarski RJ \& Flegal KM (2000) Criteria for definition of overweight in transition: background and recommendations for the United States. Am J Clin Nutr 72, 1074-1081.

10. Santé-Québec A (1994) A Health Profile of the Inuit: Report of the Santé-Québec Health Survey among the Inuit of Nunavik, 1992, Montréal.

11. McNamara JR \& Schaefer EJ (1987) Automated enzymatic standardized lipid analyses for plasma and lipoprotein fractions. Clin Chim Acta 166, 1-8.

12. Burstein M \& Samaille J (1960) On a rapid determination of the cholesterol bound to the serum alpha- and beta-lipoproteins. Clin Chim Acta 5, 609.

13. Friedewald WT, Levy RI \& Fredrickson DS (1972) Estimation of the concentration of low-density lipoprotein cholesterol in plasma, without use of the preparative ultracentrifuge. Clin Chem 18, 499-502.

14. Laurell CB (1966) Quantitative estimation of proteins by electrophoresis in agarose gel containing antibodies. Anal Biochem 15, 45-52.

15. Expert Panel on Detection, Evaluation, and Treatment of High Blood Cholesterol in Adults (2001) Executive Summary of the Third Report of the National Cholesterol Education Program (NCEP) Expert Panel on Detection, Evaluation, and Treatment of High Blood Cholesterol in Adults (Adult Treatment Panel III). JAMA 285, 2486-2497.

16. Kathiresan S, Melander O, Guiducci C, et al. (2008) Six new loci associated with blood low-density lipoprotein cholesterol, high-density lipoprotein cholesterol or triglycerides in humans. Nat Genet 40, 189-197.

17. Ordovas JM, Lopez-Miranda J, Mata P, et al. (1995) Genediet interaction in determining plasma lipid response to dietary intervention. Atherosclerosis 118, S11-S27.

18. Lopez-Miranda J, Marin C, Castro P, et al. (2000) The effect of apolipoprotein $\mathrm{B}$ xbaI polymorphism on plasma lipid response to dietary fat. Eur J Clin Invest 30, 678-684.

19. Friedlander Y, Berry EM, Eisenberg S, et al. (1995) Plasma lipids and lipoproteins response to a dietary challenge: analysis of four candidate genes. Clin Genet 47, 1-12.

20. Talmud PJ, Boerwinkle E, Xu CF, et al. (1992) Dietary intake and gene variation influence the response of plasma lipids to dietary intervention. Genet Epidemiol 9, 249-260.

21. Rantala M, Rantala TT, Savolainen MJ, et al. (2000) Apolipoprotein $\mathrm{B}$ gene polymorphisms and serum lipids: meta-analysis of the role of genetic variation in responsiveness to diet. Am J Clin Nutr 71, 713-724.

22. Lopez-Miranda J, Ordovas JM, Ostos MA, et al. (1997) Dietary fat clearance in normal subjects is modulated by genetic variation at the apolipoprotein B gene locus. Arterioscler Thromb Vasc Biol 17, 1765-1773.

23. Mata P, Lopez-Miranda J, Pocovi M, et al. (1998) Human apolipoprotein A-I gene promoter mutation influences plasma low density lipoprotein cholesterol response to dietary fat saturation. Atherosclerosis 137, 367-376.

24. Ordovas JM, Corella D, Cupples LA, et al. (2002) Polyunsaturated fatty acids modulate the effects of the APOA1 G-A polymorphism on HDL-cholesterol concentrations in a sexspecific manner: the Framingham Study. Am J Clin Nutr 75, 38-46.

25. Angotti E, Mele E, Costanzo F, et al. (1994) A polymorphism $(\mathrm{G} \rightarrow \mathrm{A}$ transition) in the -78 position of the apolipoprotein A-I promoter increases transcription efficiency. $J$ Biol Chem 269, 17371-17374.

26. Moreno JA, Perez-Jimenez F, Marin C, et al. (2004) Apolipoprotein $\mathrm{E}$ gene promoter $-219 \mathrm{G} \rightarrow \mathrm{T}$ polymorphism increases LDL-cholesterol concentrations and susceptibility to oxidation in response to a diet rich in saturated fat. $\mathrm{Am}$ J Clin Nutr 80, 1404-1409.

27. Fan YM, Raitakari OT, Kahonen M, et al. (2009) Hepatic lipase promoter C-480T polymorphism is associated with serum lipids levels, but not subclinical atherosclerosis: the Cardiovascular Risk in Young Finns Study. Clin Genet 76, 46-53.

28. Ordovas JM, Corella D, Demissie S, et al. (2002) Dietary fat intake determines the effect of a common polymorphism in the hepatic lipase gene promoter on high-density lipoprotein metabolism: evidence of a strong dose effect in this gene-nutrient interaction in the Framingham Study. Circulation 106, 2315-2321.

29. Zhang C, Lopez-Ridaura R, Rimm EB, et al. (2005) Interactions between the $-514 \mathrm{C} \rightarrow \mathrm{T}$ polymorphism of the hepatic lipase gene and lifestyle factors in relation to HDL concentrations among US diabetic men. Am J Clin Nutr 81, 1429-1435.

30. Zhang C, Lopez-Ridaura R, Rimm EB, et al. (2006) Genetic variation in the hepatic lipase gene and the risk of coronary heart disease among US diabetic men: potential interaction with obesity. Diabetologia 49, 1552-1559.

31. Zafarmand MH, van der Schouw YT, Grobbee DE, et al. (2008) The M235T polymorphism in the $A G T$ gene and CHD risk: evidence of a Hardy-Weinberg equilibrium violation and publication bias in a meta-analysis. PLoS One 3, e2533.

32. Shioji K, Mannami T, Kokubo Y, et al. (2004) An association analysis between ApoA1 polymorphisms and the high-density lipoprotein (HDL) cholesterol level and myocardial infarction (MI) in Japanese. J Hum Genet 49, 433-439.

33. Yamada Y, Matsuo H, Warita S, et al. (2007) Prediction of genetic risk for dyslipidemia. Genomics 90, 551-558.

34. Bego T, Dujic T, Mlinar B, et al. (2011) Association of PPARG and LPIN1 gene polymorphisms with metabolic syndrome and type 2 diabetes. Med Glas Ljek komore Zenicko -doboj kantona $\mathbf{8}, 76-83$.

35. Kraja AT, Province MA, Straka RJ, et al. (2010) Fenofibrate and metabolic syndrome. Endocr Metab Immune Disord Drug Targets 10, 138-148.

36. Russo GT, Meigs JB, Cupples LA, et al. (2001) Association of the Sst-I polymorphism at the APOC3 gene locus with variations in lipid levels, lipoprotein subclass profiles and coronary heart disease risk: the Framingham offspring study. Atherosclerosis 158, 173-181.

37. Lopez-Miranda J, Ordovas JM \& Marin C (1994) The SstI polymorphic site at the apolipoprotein C-III gene predicts plasma low-density lipoprotein response to changes in dietary fat in young men. Circulation $\mathbf{9 0}$, I.

38. Darabi M, Abolfathi AA, Noori M, et al. (2009) Cholesteryl ester transfer protein I405V polymorphism influences 
apolipoprotein A-I response to a change in dietary fatty acid composition. Horm Metab Res 41, 554-558.

39. Sreeja L, Syamala V, Hariharan S, et al. (2005) Possible risk modification by CYP1A1, GSTM1 and GSTT1 gene polymorphisms in lung cancer susceptibility in a South Indian population. J Hum Genet 50, 618-627.

40. Delgado-Lista J, Perez-Martinez P, Perez-Jimenez F, et al. (2010) ABCA1 gene variants regulate postprandial lipid metabolism in healthy men. Arterioscler Thromb Vasc Biol 30, 1051-1057.
41. Frikke-Schmidt R, Nordestgaard BG, Jensen GB, et al. (2008) Genetic variation in ABCA1 predicts ischemic heart disease in the general population. Arterioscler Thromb Vasc Biol 28, 180-186.

42. Kolovou V, Kolovou G, Marvaki A, et al. (2011) ATP-binding cassette transporter A1 gene polymorphisms and serum lipid levels in young Greek nurses. Lipids Health Dis 10, 56.

43. Liao YC, Lin HF, Rundek T, et al. (2008) Multiple genetic determinants of plasma lipid levels in Caribbean Hispanics. Clin Biochem 41, 306-312. 